\title{
Retraction: Guo, S., et al. Improvement in the Poverty Status of Ecological Migrants under the Urban Resettlement Model: An Empirical Study in China. Sustainability 2020, 12, 2084
}

\author{
Shijie Guo ${ }^{1,2}$, Guichang Liu ${ }^{1}$, Qi Zhang ${ }^{3}$, Fang Zhao ${ }^{4,5, *}$ and Guomin Ding ${ }^{1}$ \\ 1 School of Law, Fuzhou University, Fuzhou 350116, China; n181910001@fzu.edu.cn (S.G.); \\ m171910003@fzu.edu.cn (G.L.); dingguomin@fzu.edu.cn (G.D.) \\ 2 Faculty of Law, University of Oxford, Oxford OX1 3UL, UK \\ 3 Department of Architecture and Built Environment, University of Nottingham, Nottingham NG7 2RD, UK; \\ laxqz10@nottingham.ac.uk \\ 4 Center for China Public Sector Economy Research, Jilin University, Changchun 130012, China \\ 5 Economics School, Jilin University, Changchun 130012, China \\ * Correspondence: fang@jlu.edu.cn; Tel.: +86-138-4301-5325
}

Received: 9 December 2020; Accepted: 10 December 2020; Published: 18 December 2020

check for updates

The journal retracts the article "Improvement in the Poverty Status of Ecological Migrants under the Urban Resettlement Model: An Empirical Study in China" by Guo et al. [1].

Following publication, concerns were brought to the attention of the publisher regarding overlap with a previously published academic paper, published in another language, of a different authorship [2]. The overlap includes the literature review, theoretical and methods sections, analytical framework and discussions, as well as a number of identical figures and tables.

Adhering to our complaints procedure, an investigation was conducted that confirmed significant overlaps with the previous manuscript, and the article is therefore retracted.

This retraction was approved by the Editor in Chief of the journal Sustainability.

The authors agreed to this retraction.

\section{References}

1. Guo, S.; Liu, G.; Zhang, Q.; Zhao, F.; Ding, G. Improvement in the Poverty Status of Ecological Migrants under the Urban Resettlement Model: An Empirical Study in China. Sustainability 2020, 12, 2084. [CrossRef]

2. Guo, H.; Li, J. Impact of urban resettlement on the livelihood activities of rural resettled households in Southern Shaanxi Province with method of Coarsened Exact Matching (CEM). China Popul. Resour. Environ. 2019, 29, 149-156. (In Chinese)

Publisher's Note: MDPI stays neutral with regard to jurisdictional claims in published maps and institutional affiliations.

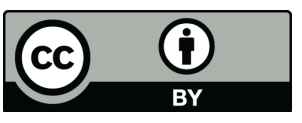

(C) 2020 by the authors. Licensee MDPI, Basel, Switzerland. This article is an open access article distributed under the terms and conditions of the Creative Commons Attribution (CC BY) license (http://creativecommons.org/licenses/by/4.0/). 